\title{
Severe Acute Malnutrition among Hospitalized Children, Aden, Yemen
}

\author{
Mohammed Ali Badi, Iman Ali Ba-Saddik* \\ Pediatric Department, Faculty of Medicine and Health Sciences, University of Aden, Aden, Yemen \\ Email: "imanmakki@gmail.com
}

Received 23 February 2016; accepted 10 May 2016; published 13 May 2016

Copyright (C) 2016 by authors and Scientific Research Publishing Inc.

This work is licensed under the Creative Commons Attribution International License (CC BY). http://creativecommons.org/licenses/by/4.0/

(c) (i) Open Access

\begin{abstract}
Objective: Severe acute malnutrition (SAM) is one of the most common causes of morbidity and mortality among children under 5 years of age worldwide. The aim of this study was to find out the prevalence of SAM among hospitalized children at Al-Wahda teaching hospital in Aden, Yemen. Methods: This descriptive cross-sectional hospital based study was conducted on 622 hospitalized children (336 males and 286 females) below 6 years of age during 2012-2013. SAM was defined as a very low weight for height (below-3 $\mathrm{Z}$ scores of the median WHO growth standards). Results: SAM was diagnosed in 622 children with prevalence rate of $5.2 \%$ from total 11,941 admissions during 24 months period. A higher proportion of patients were marasmus $586(94.2 \%)$ and only $36(5.8 \%)$ were kwashiorkor. Marasmus was common in $<1$ year of age in $347(59.2 \%)$ while kwashiorkor between 1 - 5 years in $22(61.1 \%)$ patients. Males $(54 \%)$ predominated females (46\%) with a male to female ratio of 1.18:1 in SAM but with no significant difference in sex. The highest comorbidities with SAM were gastroenteritis 442 (71.1\%) and 103 pneumonia (16.6\%) with a total cure of $492(79.1 \%)$ patients. Conclusion: This high prevalence of SAM among males who were $<5$ years of age with high risk of gastroenteritis and pneumonia added weight to the urgent need to improve the nutritional status of children.
\end{abstract}

\section{Keywords}

Severe Acute Malnutrition, Marasmus, Kwashiorkor

\section{Introduction}

Severe acute malnutrition (SAM) is one of the most common causes of morbidity and mortality among children under the age of 5 years worldwide. Many severely malnourished children die at home without care, but even

${ }^{*}$ Corresponding author. 
when hospital care is provided, case fatality rates may be high [1]. Severe acute malnutrition is defined as a very low weight for height below-3 Z scores of the median WHO growth standards; in accordance with the last recommendations of WHO Expert Committeein Malnutrition [2].

SAM has two forms, kwashiorkor and marasmus that are differentiated on the basis of clinical findings, with the primary difference being the presence of oedema in kwashiorkor. Kwashiorkor is due to adequate carbohydrate consumption and decreased protein intake which leads to decreased synthesis of visceral proteins. Kwashiorkor is common in children of both sexes, aged 1 - 3 years, but it can occur in younger or older children. The signs of kwashiorkor may appear very quickly, often when a child has an infection, or stops breastfeeding suddenly. Kwashiorkor presents with edema, usually seen in the feet, lower legs and arms where in severe cases it may also be seen in the upper limbs and face. Children with kwashiorkor have moon face, moderately low weight, wasted and weak muscles, misery and apathy with anorexic. They also present with hair and skin changes to lightly or brownish colouration, dermatosis, and usually have fatty hepatomegaly [3].

Marasmus is described as an insufficient energy and nutrient intake seen mainly in infants between 6 to 8 months of age but may occur in children less than 5 years old. It often follows severe illness or a period of frequent infections. Marasmus is below-3 Z-scores without edema. Marasmus presents with severe wasting and have lost fat and muscle with an "old person s face", dry loose wrinkled patchy skin, prominent bones and joints. There are folds of skin on the buttocks and thighs with pot belly, irritability, hunger and absence of oedema [3].

According to WHO's report, 27\% of children under five years of age in developing countries are underweight that caused about 3.4 million deaths during the year 2000, where 1.2 million of which happened in Asian countries [4]. The prevalence of SAM among children under 5 years of age was reported in several developing countries, (Africa 8\%, Asia 10\%, Latin America and Caribbean 3\%, Oceania 5\%) [5].

Marasmic-Kwashiorkor formed 9.9\% of the total number of admitted cases in Nigeria [3]. The prevalence of marasmus was highest in the 6 to 12 months age groups of (34.3\%) and (36\%) for males and females, respectively. Kwashiorkor was highest among the children in 13 to 18 months age group for both sexes [6]. In Botswana, the level of malnutrition among children under three years of age was 5.5\% (wasting), 38.7\% (stunting) and $15.6 \%$ (underweight) [7]. The prevalence of wasting, stunting, and wasting and stunting was $31.2 \%, 9.4 \%$, and $29.2 \%$ respectively among Indian children with predominance of wasting among the younger age groups [8].

There are many problems related to the treatment of severely malnourished children who die from incorrect management. As a result, mortality rates as high as $40 \%-50 \%$ are found in many different hospitals [9]. Factors contributing to the development of SAM include a combined series of environmental nutritional, clinical, cultural and social practices that lead to the exclusion of certain foods due to food taboos, food and dietary fads and migration from rural areas to urban slums [10] [11]. Dietary choices are influenced by parents' nutritional ignorance, preference for alternative foods and true or perceived food allergies [12].

The socioeconomic status plays a major contributing role in the types of nutrition that is when the income decreases, the quality and quantity of food also decreases. Evidence shows that when unemployment and low wages are presenting factors, families eat cheaper food, which is less nutritious, leading to weight loss and malnutrition [13]. SAM is particularly serious in post-weaning and often associated with infections. The most common diseases associated with SAM are respiratory infection. Pneumonia is common in malnourished children and frequently associated with fatal outcome, while diarrhea and vomiting lead to high morbidity [14]. SAM has effect on growth and development of children, learning ability and social adjustment [6]. In addition, it has consecutively caused the mortality of children and their physical disturbance; leading to lack of economic and social development in these countries [15].

The objective of the present study was to determine the prevalence of severe acute malnutrition in a population of children admitted at Al-Wahda teaching hospital in Aden city, Yemen.

\section{Patients and Methods}

This is a descriptive cross-sectional hospital based study. The studied population included all children of both sexes admitted in the nutritional unit of Al-Wahda teaching hospital in Aden, Yemen, within the period of study 2012-2013, with available records diagnosed as severe acute malnutrition. There were a total of six hundred and twenty two (336 males and 286 females) children. The children were between the ages of 1 and 72 months with a mean age (13.7) SD of (1.5) months.

The weight of every child was measured by means of a German Seca scale with the accuracy of $\pm 50 \mathrm{gm}$. The height of every child was measured by means of a height-measurer, the accuracy of which was 0.5 centimeter in 
standard situation while each case had the least clothes and no shoes on (the height of over 2 year of age was measured in standing position and that of under 2 years of age in supine position).

The Z-score was used to differentiate between normal condition and malnutrition. SAM classification was in accordance with the last recommendations of WHO Expert Committee in Malnutrition, and the last WHO growth reference standards were used [2]. The patients were classified into two groups, Kwashiorkor and Marasmus, using WHO malnutrition classification [2]. An open questionnaire was completed for each patient in which demographic variables, clinical features, diagnosis and outcome were recorded. The studied variables included the age in (years), sex, residency of the children, diagnosis and the associated common diseases, with the outcome classified into cure, discharge against medical advice (DAMA) and death that were obtained from the records of the patients in Al-Wahda hospital.

The written consent was obtained from the parents or child guardian. The ethical approval was obtained from the administration office of the hospital and the objectives of the study were justified and the information collected was kept totally confidential. Data were processed and analyzed by the SPSS software version 15 . The chi square test, with a significance level of $5 \%(\mathrm{p}<0.05)$, was used to determine the possible relationship between SAM and age group, sex, residency, diagnoses and outcome.

\section{Results}

A total of 622 patients were admitted with SAM comprising a prevalence rate of $5.2 \%$ from the total admissions of 11,941 during the period of study 2012-2013. The male to female ratio was 1.18:1 in children with SAM under 6 years of age. 361 (58.0\%) of the children were less than one year and 254 (40.8\%) were between 1 - 5 years and 7 (1.1\%) were over than 5 years (Table 1$)$.

A total of 586 (94.2\%) of the patients were classified under marasmus and only 36 (5.8\%) were diagnosed as kwashiorkor. The results showed that the percentage of marasmus was higher in the age group < one year and kwashiorkor was highest among the children in the age group 1 - 5 years with respect to the other groups. The results indicated the proportion of patients with marasmus was higher than kwashiorkor both in males and females respectively, (94.6\%, 93.7\% versus 5.4\%, 6.3\%), but the difference was not significant.

There was no significant relationship $(p>0.05)$ between residency and the percentage of SAM in the children, although the percentage of SAM was higher in Aden city 59.7\% than other governorates $40.3 \%$ (Table 2).

Among the different diagnoses, the greatest risk for malnutrition was found in children with gastroenteritis (71.1\% malnourished), pneumonia (16.6\%) and cerebral palsy (4.3\%) in comparison to the other groups. There was statistically significant relationship $(\mathrm{p}<0.05)$ between the different associated diseases and the percentage of SAM in the children (Table 3).

Table 1. Severe acute malnutrition among hospitalized children by age group and sex in Aden, Yemen.

\begin{tabular}{|c|c|c|c|c|c|c|}
\hline $\begin{array}{l}\text { Age Group } \\
\text { (years) }\end{array}$ & Sex & Marasmus & Kwashiorkor & Total (\%) & Grand Total & (p) \\
\hline & & No (\%) & No (\%) & No (\%) & No (\%) & \\
\hline \multirow[b]{2}{*}{$<1$} & Male & 186 & 7 & $193(57.4)$ & \multirow{2}{*}{$\begin{array}{c}361 \\
(58.0)\end{array}$} & \multirow[t]{2}{*}{0.501} \\
\hline & Female & 161 & 7 & $168(58.7)$ & & \\
\hline \multirow[b]{2}{*}{$1-5$} & Male & 130 & 11 & $141(42)$ & \multirow[b]{2}{*}{$254(40.8)$} & \multirow[b]{2}{*}{0.37} \\
\hline & Female & 102 & 11 & 113 (39.5) & & \\
\hline \multirow{2}{*}{$>5$} & Male & 2 & - & $2(0.6)$ & \multirow{2}{*}{$\begin{array}{c}7 \\
(1.1)\end{array}$} & \\
\hline & Female & 5 & - & $5(1.7)$ & & \\
\hline \multirow{2}{*}{ Total } & Male & 318 (94.6) & $18(5.4)$ & $336(54)$ & \multirow{2}{*}{$\begin{array}{c}622 \\
(100)\end{array}$} & \\
\hline & Female & 268 (93.7) & $18(6.3)$ & $286(46)$ & & \\
\hline $\begin{array}{c}\text { Grand } \\
\text { Total }\end{array}$ & & 586 (94.2) & 36 (5.8) & $622(100)$ & & \\
\hline
\end{tabular}


Table 2. Severe acute malnutrition among hospitalized children by residency in Aden, Yemen.

\begin{tabular}{|c|c|c|c|}
\hline \multirow[t]{2}{*}{ Regions } & \multicolumn{2}{|c|}{ Severe Acute Malnutrition } & \multirow[t]{2}{*}{ P Value } \\
\hline & No & $\%$ & \\
\hline Aden & 371 & 59.6 & \\
\hline Lahej & 94 & 15.1 & \\
\hline Abyan & 91 & 14.6 & 0.224 \\
\hline Yafee & 35 & 5.6 & \\
\hline Shabwa & 12 & 1.9 & \\
\hline Others & 19 & 3.1 & \\
\hline Total & 622 & 100.0 & \\
\hline
\end{tabular}

Table 3. Severe acute malnutrition among hospitalized children by co-morbidities in Aden, Yemen.

\begin{tabular}{|c|c|c|c|c|c|}
\hline \multirow[t]{2}{*}{ Co-Morbidities } & \multirow[t]{2}{*}{ No (\%) } & \multicolumn{4}{|c|}{ Age Groups (years) } \\
\hline & & $<1$ & $1-5$ & $>5$ & (p) \\
\hline Gastroenteritis & $442(71.1)$ & 255 & 183 & 4 & \multirow{9}{*}{0.001} \\
\hline Pneumonia & $103(16.6)$ & 62 & 40 & 1 & \\
\hline Cerebral Palsy & $27(4.3)$ & 12 & 15 & 0 & \\
\hline C.H.D. & $21(3.4)$ & 14 & 7 & 0 & \\
\hline TB & $13(2.1)$ & 7 & 4 & 2 & \\
\hline U.T.I & $8(1.3)$ & 3 & 5 & 0 & \\
\hline Megacolon & $5(0.8)$ & 5 & 0 & 0 & \\
\hline Malaria & $3(0.5)$ & 3 & 0 & 0 & \\
\hline Total & $622(100)$ & 361 & 254 & 7 & \\
\hline
\end{tabular}

The percentage of outcome in SAM was higher in cure groups (79.1\%) than the DAMA and dead groups (14.3\% and 6.6\%) respectively. although the results were not significant (Table 4).

\section{Discussion}

Sever acute malnutrition at Al-Wahda teaching hospital in Aden for the period of 24 months was studied in this work which showed a prevalence rate of $5.2 \%$ from the total number of hospitalized children. This did not show any difference from the study in Mozambique (6\%) [11]. The observation of a greater number of pediatric patients with marasmus 586 (94.2\%) compared with those of kwashiorkor 36 (5.8\%) respectively, was in agreement with the report in Nigeria and South Africa [6] [16].

In this study, there was no significant difference between age group and sex with respect to SAM. Marasmus cases 347 (59.2\%) were found to be more common among children less than 12 months of age while kwashiorkor $22(61.1 \%)$ was highest between 12 to 60 months of age. SAM was higher among males compared to females (54\% versus $46 \%$ ) which falls in agreement with a study in South African (59.3\% males vs.40.7\% females) respectively [16]. This could probably be explained by the fact of inadequate calorie intake with poor protein in the diet, where a greater percentage of the diet in Aden and the neighboring regions are mainly based on rice and bread which is made from carbohydrate. People cannot afford to buy foods rich in protein as fish and meat which is quite expensive.

Other factors leading to nutrient deficiencies and low energy and protein intakes seen in children are the increased use of diluted cow's milk and less amount of vegetable foods given and a delay in giving children family foods [17]. On the other hand, babies are sometimes weaned too early because of another birth, causing the mother to cease breastfeeding of the first baby. Babies are then often weaned on a thin cereal with low quality protein, causing the older child to become ill when the new baby arrives. Children cannot obtain food for themselves [18]; and they have small gastric capacities, meaning they are incapable of ingesting large amounts of sufficient food. This in turn can lead to malnutrition [10]. 
Table 4. Severe acute malnutrition among hospitalized children by outcome in Aden, Yemen.

\begin{tabular}{|c|c|c|c|c|c|}
\hline Nutritional Status & & Outcome & & & p Value \\
\hline & Cure & DAMA & Dead & Total & \\
\hline & No (\%) & No (\%) & No (\%) & No (\%) & \\
\hline Marasmus & 465 (79.4) & 84 (14.3) & $37(6.3)$ & $586(100)$ & 0.530 \\
\hline Kwashiorkor & $27(75.0)$ & $5(13.9)$ & $4(11.1)$ & 36 (100) & \\
\hline Total & $492(79.1)$ & $89(14.3)$ & $41(6.6)$ & $622(100)$ & \\
\hline
\end{tabular}

There is not enough information available on the prevalence of severe or edematous malnutrition in the communities. The data available from hospitals only shows the severe cases and therefore malnutrition in general is not always recorded because in most cases it is the secondary diagnosis [19]. There is a greater likelihood that children under one year are probably more prone to malnutrition and require more nutritive care and attention to their health.

The percentage of SAM in Aden city was $59.6 \%$ but in the neighboring governorates was $40.4 \%$ that is comparably higher than the rural report of Birjand (32.4\%) [20]. The prevalence of (SAM) was 20.5\% in Nigeria [21] and $2.9 \%$ in a poor area in China [22], meaning their nutritional states was too low for their age. A higher proportion of the malnourished children in this study were residents in high-density areas or areas of the town which have poor facilities in their homes, inadequate environmental sanitation and low socioeconomic status of the patients. Generally these problems were probably identified as key factors for SAM.

Because the children are the victims of poverty, political instability and acute deprivation of living facilities, recent droughts in the rural, and finally unfavorable nutrition of children all over the governorate are the reasons for the severe acute malnutrition. This is worth thinking and working towards more nutritional solutions [23].

This study also showed no significant relationship between SAM and the associated diseases or co-morbidities, although, the percentage of gastroenteritis (71.1\%), pneumonia (16.6\%) and cerebral palsy (4.3\%) were in a higher proportion. These findings do not coincide with reports of several countries where gastroenteritis was reported in $23.6 \%$, neurologic diseases in $40 \%$ and infectious diseases in 34.5\% [24]. Sanchez-Lastres et al. reported that the prevalence of malnutrition increased in patients with cerebral palsy [25]. On the contrary a report from Iran showed the prevalence of gastroenteritis in SAM to be $10.3 \%$ while in India diarrhea was reported in $54 \%$ and respiratory tract infections in $27.8 \%$ [26] [27].

This has been attributed to the fact that in SAM, the intestinal epithelium may be markedly abnormal, the villi are shortened or flat and the crypts are deepened. A few children show malabsorption of starch and other complex carbohydrates. Reduced feeding, or continued feeding of an inappropriate diet, causes further weight loss [9].

In pneumonia, factors contributing to the increased mortality risk include immunodeficiency associated with malnutrition, high rates of co-morbidities, delayed health-seeking behaviour among families of children with malnutrition, and delayed diagnosis due to the unawareness of the clinical signs [14]. Significant advances have been made in understanding the vicious cycle of malnutrition, diarrhea, and pneumonia in developing countries. Future challenges will have to make this progress more effective and widely accessible and usable among the public health measures.

Patients with cerebral palsy experience communication difficulties which makes them unable to request food and drink. Such difficulties include unable to swallow, hyperactive gag reflex, and inability to control feeding leading to increased risk of SAM in children with cerebral palsy [28] [29]. Thus prevalence of SAM with mixed diagnosis ranges from $6.1 \%$ to $31.8 \%$ [30]. Children with an underlying disease usually have a high rate of malnutrition. Nowadays, there are many specific growth references for patients with coexisting diseases that might give more appropriate assessments on nutrition [31].

This study did not show any significant relationship between SAM and the outcome among hospitalized children, although SAM was higher in the cure group (79.1\%) compared to the others. The patients who had a fatal outcome and died comprised a case fatality rate of (6.6\%) was almost similar to a study in Mozambique (7.1\%) but comparably less to other countries, (Congo 21\%, Bangladesh 20\%, Senegal 20\%, Uganda 12\%, Yemen 10\%, Columbia 10\%) [11] [29] [32]. This may be probably explained by the fact of the reflection of the effective role of doctors and hospital staff who were continuously trained with supports from the UNICEF as well 
as the services and intervention that were successfully provided by the UNICEF in the nutritional unit of this hospital.

However, as this is a hospital-based study further community based studies are recommended toknow the prevalence for severe acute malnutrition. These patients who were admitted to the hospital probably had better affordability and accessibility than others who might not have been able to reach to the hospital. The authors also sought to reduce the study bias for misclassification of the patients by reviewing all admission clinical findings and derived independent diagnoses of kwashiorkor and marasmus using the WHO classification.

\section{Conclusion}

In this study, there is a high prevalence of SAM in both sexes among hospitalized children below five years of age. It is of great importance to promote the knowledge and health education of parents, particularly mothers. It is also recommended to establish nutrition support teams in pediatric hospitals with the primary role of screening high risk children for nutritional problems, to identify patients who require nutritional support, to provide adequate nutritional management, to educate and train hospital staff, and to audit practice. Furthermore, the high prevalence of malnutrition in pediatric patients adds further future weight to the urgent need to implement these recommendations. This is mainly the responsibility of the authorities to seek solutions to such problems and to create the clinical nutritional center in each hospital.

\section{Acknowledgements}

Authors would like to thank children, stuff nurse and archives workers in the nutritional unit in Al-Wahda teaching hospital of Aden governorate for their cooperation in this study.

\section{References}

[1] World Health Organization (WHO) (2006) Training Course on the Management of Severe Malnutrition. WHO Department of Nutrition for Health and Development (NHD), Geneva.

[2] World Health Organization (WHO) (2006) Multicentre Growth Reference Study Group. WHO Child Growth Standards Based on length/Height, Weight/Age. Acta Paediatrica, 450, 76-85.

[3] Jamabo, T. and Onwukwe, A.O. (2010) The Incidence of Marasmic-Kwashiorkor among Children in Port Harcourt, Nigeria. Nigerian Journal of Agriculture, Food and Environment, 6, 96-100.

[4] WHO (2002) World Health Report. World Health Organization, Geneva.

[5] Müller, O. and Krawinkel, M. (2005) Malnutrition and Health in Developing Countries. Canadian Medical Association Journal, 173, 279-286. http://dx.doi.org/10.1503/cmaj.050342

[6] Hamidu, J.L., Salami, H.A., Ekanem, A.U. and Hamman (2003) Prevalence of Protein—Energy Malnutrition in Maiduguri, Nigeria. African Journal of biomedical Research, 6, 123-127.

[7] Salah E.O., Mahgoub, M.N. and Theodore, B. (2006) Factors Affecting Prevalence of Malnutrition Among\Children under Three Years of Age in Botswana. African Journal of Food, Agriculture, Nutrition and Development, 6.

[8] Joseph, B., Rebello, A., Kullu, P. and Vimal, D. (2002) Prevalence of Malnutrition in Rural Karnataka, South India: A Comparison of Anthropometric Indicators. Journal of Health, Population and Nutrition, 20, 239-244.

[9] World Health Organization (2004) Serious Childhood Problems in Countries with Limited Resources. Department of Child and Adolescent Health and Development. World Health Organization, Geneva.

[10] Torún, B. (2006) Protein-Energy Malnutrition. In: Shils, Maurice, E., Shike and Moshe, Eds., Modern Nutrition in Health and Disease, 10th Edition, Lippincott Williams \& Wilkins, Philadelphia, 881-906.

[11] Nhampossa, T. (2013) Severe Malnutrition among Children under the Age of 5 Years Admitted to a Rural District Hospital in Southern Mozambique. Public Health Nutrition, 16, 1564-1574. http://dx.doi.org/10.1017/S1368980013001080

[12] Katz, K.A., Mahlberg, M.H., Honig, P.J. and Yan, A.C. (2005) Rice Nightmare: Kwashiorkor in 2 Philadelphia-Area Infants Fed Rice Dream Beverage. Journal of the American Academy of Dermatology, 52, S69-S72. http://dx.doi.org/10.1016/j.jaad.2004.07.056

[13] United Nations Children's Emergency Fund (2009) A Matter of Magnitude: The Impact of the Economic Crisis on Women and Children in South Asia.

[14] Chisti, M.J., Tebruegge, M., La Vincente, S., Graham, S.M. and Duke, T. (2009) Pneumonia in Severely Malnourished 
Children in Developing Countries-Mortality Risk, Aetiology and Validity of WHO Clinical Signs: A Systematic Review. Tropical Medicine \& International Health, 14, 1173-1189. http://dx.doi.org/10.1111/j.1365-3156.2009.02364.X

[15] Mahan, L.K. (2004) Medical Nutrition Therapy. In: Mahan, L.K. and Escott-Stump, S., Eds., Krause’s Food Nutrition and Diet Therapy, 11th Edition, Saunders, Philadelphia, 74-76.

[16] Johanna, C. (2010) Factors Contributing to Malnutrition in Children 0 - 60 Months Admitted to Hospitals in the Northern Cape. Department of Nutrition and Dietetics, University of the Free State, South Africa.

[17] Kapur, D., Sharma, S. and Agarwal, K.N. (2005) Dietary Intake and Growth Pattern of Children 9 - 36 Months of Age in an Urban Slum in Delhi. Indian Pediatrics, 42, 351-356.

[18] Golden, M.H.N. and Golden, B.E. (2000) Severe Malnutrition. In: Garrow, J.S. and James, W.P.T., Eds., Human Nutrition and Dietetics, 10th Edition, Churchill Livingstone, London, 515-525.

[19] Duggan, M. and Golden, B. (2005) Deficiency Diseases. In: Geissler, C. and Powers, H., Eds., Human Nutrition, 11th edition, Elsevier Churchill Livingstone, London.

[20] Wang, X., Hojer, B. and Guo, S. (2009) Stunting and Overweight in the WHO Child Growth Standards. Malnutrition among Children in a Poor Area of China. Public Health Nutrition, 12, 1991-1998. http://dx.doi.org/10.1017/S1368980009990796

[21] Senbanjo, I.O., Adeodu, O.O. and Adjuyigbe, E.A. (2007) Low Prevalence of Malnutrition in a Rural Nigerian Community. Tropical Doctor, 37, 214-216. http://dx.doi.org/10.1258/004947507782333161

[22] Cui, Y., Yang, L. and Zhao, Y.X. (2008) Study on Status of Nutrition in Children under Three Years Old in Rural Area in China. Chinese Journal of Epidemiology, 29, 230-240.

[23] Gholamreza, S., Hassan, M. and Soori, R. (2010) Prevalence of Malnutrition in under 6-Year Old in South Khorasan, Iran. Iranian Journal of Pediatrics, 20, 435-441.

[24] Pawellek, I., Dokoupil, K. and Koletzko, B. (2008) Prevalence of Malnutrition in Pediatric Hospital Patients. Clinical Nutrition, 27, 72-76. http://dx.doi.org/10.1016/j.clnu.2007.11.001

[25] Sanchez, L.J., Eiris, P.J. and Otero, C.L. (2003) Nutritional Status of Mentally Retarded Children in North-West Spain. Anthropometric Indicators. Acta Paediatrica, 92, 747-753. http://dx.doi.org/10.1111/j.1651-2227.2003.tb00612.x

[26] Yilgwan, C.S. and Okolo, S.N. (2012) Prevalence of Diarrhea Disease and Risk Factors in Jos University Teaching Hospital, Nigeria. Annals of African Medicine, 11, 217-221. http://dx.doi.org/10.4103/1596-3519.102852

[27] Kumar, R., Singh, J., Joshi, K., Singh, H.P. and Bijesh, S. (2014) Co-Morbidities in Hospitalized Children with Severe Acute Malnutrition. Indian Pediatrics, 51, 125-127. http://dx.doi.org/10.1007/s13312-014-0343-x

[28] Kuperminc, M.N. and Stevenson, R.D. (2008) Growth and Nutritional Disorders in Children with Cerebral Palsy. Developmental Disabilities Research Reviews, 14, 137-146. http://dx.doi.org/10.1002/ddrr.14

[29] WHO (2007) Community-Based Management of Severe Acute Malnutrition. A Joint Statement by the WHO, WFP, UNSSCN and UNICEF, Geneva.

[30] Joosten, K.F.M. and Hulst, J.M. (2008) Prevalence of Malnutrition in Paediatric Hospital Patients. Current Opinion in Pediatrics, 20, 590-596. http://dx.doi.org/10.1097/MOP.0b013e32830c6ede

[31] Koen, F.M., Joosten, K.F.M. and Hulst, J.M. (2011) Malnutrition in Pediatric Hospital Patients: Current Issues. Nutrition, 27, 133-137. http://dx.doi.org/10.1016/j.nut.2010.06.001

[32] Campos, M.G., Perez-Navero, J., Patino, C.A.H., Delgado, G. and Prada, D.R. (2011) Using of WHO Guidelines for the Management of Severe Malnutrition to Cases of Marasmus and Kwashiorkor in a Columbian Children's Hospital. Nutrición Hospitalaria, 26, 977-983. 